\title{
The biometric parameters of aniso- astigmatism and its risk factor in Chinese preschool children: the Nanjing eye study
}

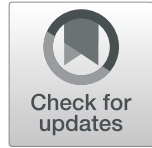

Haohai Tong ${ }^{1 \dagger}$, Qingfeng Hao ${ }^{1 \dagger}$, Zijin Wang ${ }^{1 \dagger}$, Yue Wang ${ }^{1}$, Rui Li ${ }^{1}$, Xiaoyan Zhao ${ }^{1}$, Qigang Sun ${ }^{2}$, Xiaohan Zhang ${ }^{3}$, Xuejuan Chen ${ }^{1}$, Hui Zhu', Dan Huang ${ }^{4}$ and Hu Liu' ${ }^{1 *}$

\begin{abstract}
Backgrounds: Aniso-astigmatism may hinder normal visual development in preschool children. Knowing its prevalence, biometric parameters and risk factors is fundamental to children eye care. The purpose of this study was to determine the biometric components of aniso-astigmatism and associated maternal risk factors in Chinese preschool children.

Methods: In the population-based, prospective cohort Nanjing Eye Study, children were measured for noncycloplegic refractive error using an autorefractor and for biometric parameters using an optical low-coherent reflectometry. The difference of total astigmatism (TA) between both eyes was calculated using cylinder power (non-vectorial aniso-TA was defined as $\geq 1.00$ Dioptre Cylinder [DC] between both eyes) and by vector analysis (vectorial aniso-TA was defined as a difference of $\geq 0.5$ in $J_{0}$ or $J_{45}$ between both eyes which is equivalent to 1.00 DC). The prevalence of aniso-TA was presented. Interocular biometric parameters were compared between with vs. without aniso-astigmatism group. In addition, risk factors were determined using multivariate logistic regression model.

Results: Of 1131 children (66.90 \pm 3.38 months, 53.31\% male), the prevalence of non-vectorial aniso-TA was 1.95\% (95\% Confidence Interval $(\mathrm{Cl})=1.14-2.75 \%$ ), while the prevalence of vectorial aniso-TA was twice as common as non-vectorial aniso-TA, neither varying with sex or age. With aniso-TA eyes were more asymmetric in axial length and corneal curvature radius than without aniso-TA eyes. In multivariate logistic regression model, 5-min Apgar score less than 7 was significantly associated with higher risk of aniso-TA (vectorial aniso-TA: Odds Ratio $(O R)=6.42$, $95 \% \mathrm{Cl}=2.63-15.69, P<0.001$; non-vectorial aniso-TA: $\mathrm{OR}=4.99,95 \% \mathrm{Cl}=1.41-17.68, P=0.01)$. Being twin or triple was significantly associated with higher risk of vectorial aniso-CA $(\mathrm{OR}=2.43,95 \% \mathrm{Cl}=1.05-5.60, P=0.04)$. Pre-term delivery $(O R=2.60,95 \% \mathrm{Cl}=1.09-6.15, P=0.03)$ and post-term delivery $(\mathrm{OR}=3.61,95 \% \mathrm{Cl}=1.31-9.96, P=0.01)$ were significantly associated with higher risk of vectorial aniso-CA.

(Continued on next page)
\end{abstract}

\footnotetext{
*Correspondence: liuhu@njmu.edu.cn

${ }^{\dagger}$ Haohai Tong, Qingfeng Hao and Zijin Wang contributed equally to this work.

'Department of Ophthalmology, The First Affiliated Hospital with Nanjing Medical University, 300 Guangzhou Road, Nanjing 210029, China Full list of author information is available at the end of the article
}

(c) The Author(s). 2021 Open Access This article is licensed under a Creative Commons Attribution 4.0 International License, which permits use, sharing, adaptation, distribution and reproduction in any medium or format, as long as you give appropriate credit to the original author(s) and the source, provide a link to the Creative Commons licence, and indicate if changes were made. The images or other third party material in this article are included in the article's Creative Commons. licence, unless indicated otherwise in a credit line to the material. If material is not included in the article's Creative Commons licence and your intended use is not permitted by statutory regulation or exceeds the permitted use, you will need to obtain permission directly from the copyright holder. To view a copy of this licence, visit http://creativecommons.org/licenses/by/4.0/. The Creative Commons Public Domain Dedication waiver (http://creativecommons.org/publicdomain/zero/1.0/) applies to the data made available in this article, unless otherwise stated in a credit line to the data. 
(Continued from previous page)

Conclusions: Both corneal curvature radius and axial length asymmetry were correlated with aniso-TA. Children with 5-min Apgar score $<7$ were more likely to have aniso-TA, while twin or triple, pre-term or post-term delivery were more likely to have vectorial aniso-CA.

Keywords: Aniso-astigmatism, Apgar score, Preschool children, Population-based study

\section{Background}

Astigmatism occurs when incident light rays do not converge at a single focal point [1]. It can lead to substantial visual dysfunction due to visual torsion, metamorphosis, asthenopia and reduced accommodation response $[2,3]$. Some studies suggest astigmatism may also be associated with myopia progression [4, 5]. Anisometropia is an interocular asymmetry in refraction that can be associated with strabismus, amblyopia, aniseikonia, and reduced stereopsis [6-9]. Vision In Preschoolers Study Group (VIP) has demonstrated that non-vectorial anisoastigmatism was more related with unilateral amblyopia than isometropia [10]. Thus aniso-astigmatism may bring damage to visual development in preschool children.

Previous studies have been focusing on risk factors for astigmatism [11-13]. Maternal smoking during pregnancy, caesarean section, darker iris colour, Hispanic, African American, and Asian race might be risks factor of astigmatism. Few studies explore the risk factors for aniso-astigmatism except the Sydney Myopia Study and the Shandong Children Eye Study [14, 15]. It remains unclear whether maternal factors are associated with aniso-astigmatism in Chinese preschool children. Furthermore, vectorial feature of astigmatism was rarely considered while analyzing the risk factors for anisoastigmatism [10, 16, 17]. However, initial oblique astigmatism is more likely to be associated with amblyopia than orthogonal astigmatism, even with a small degree $[18,19]$. Thus, cylinder axis should not be neglected.

The aim of this study was to describe the characteristics of aniso-TA using cylinder power and by vector analysis, to compare the interocular biometric parameters between with aniso-astigmatism group and without aniso-astigmatism group and to determine risk factors for aniso-astigmatism including vectorial aniso-total astigmatism (vectorial aniso$\mathrm{TA})$, non-vectorial aniso-TA, vectorial aniso-corneal astigmatism (vectorial aniso-CA) and vectorial aniso-residual astigmatism (vectorial aniso-RA) in a population-based Nanjing Eye Study (NES).

\section{Methods}

\section{Study design}

The NES was designed to prospectively observe the onset and progression of childhood ocular diseases in eastern China, which is an ongoing population-based open cohort study. All study procedures were approved by the institutional review board in The First Affiliated Hospital with Nanjing Medical University and were conducted according to the tenets of the Declaration of Helsinki. Written consent was obtained from the parents or guardians of all children. This study comprised 61- to 72-month-old children enrolled in kindergartens in the Yuhuatai District of Nanjing City in Eastern China. Data from eye examinations and questionnaire presented in this paper were collected in 2017.

\section{Ocular examinations and questionnaires}

Noncycloplegic autorefraction of both eyes using an autorefractor (Cannon RF10; Canon, Tokyo, Japan), measurement of biometric parameters using the optic low-coherent reflectometer (LenStar LS-900; Haag-Streit AG, Koeniz, Switzerland) and other comprehensive eye examinations were performed among all children. Measurement of autorefraction is performed 3 times as selected in the SET mode. While measuring biometric parameters, three consecutive scans were performed. Scans were operated without pupil dilation, in a dimly lit room according to the manufacturers' guidelines. If the signal-to-noise ratio (SNR) was less than 2.1, another measurement was taken until reliable readings were achieved from each eye. Biometric parameters refer to central corneal thickness (CCT), corneal radius (CR), anterior chamber depth (ACD), lens thickness (LT) and axial length (AL). A comprehensive questionnaire was distributed to legal guardians of each child. The examining procedures and content of the questionnaire have been described in detail previously [20,21]. The Apgar score is the most widely used index to report the health status of a newborn [22], which is usually evaluated from the following 5 aspects: appearance (color), pulse (heart rate), grimace response (reflexes), activity (muscle tone) and respiration (breathing rate and effort) at 1, 5 and 10 mins after delivery, with the range being 0-10 [23]. In particular, the 5-min Apgar score is categorized as normal $(\geq 7)$ and abnormal $(<7)$ in this study.

\section{Definition}

Definition and calculations of TA, CA and RA were described in previous publications. The vector method modified by Thibos was used to decompose vectorial aniso-astigmatism. The calculations are as follows [24]: 


$$
\begin{aligned}
& S E=S+C / 2 \\
& J_{0}=(-C / 2) \times(\cos 2 A) \\
& J_{45}=(-C / 2) \times(\sin 2 A)
\end{aligned}
$$

where $S E$ is the spherical equivalent, $S$ is sphere, $C$ is the cylinder in minus format, $A$ is the cylinder axis, $J_{O}$ and $J_{45}$ are the horizontal or vertical and oblique vectors of the cylinder, respectively.

The difference of TA between both eyes was calculated using cylinder power (non-vectorial aniso-TA was defined as $\geq 1.00$ Dioptre Cylinder [DC] between both eyes) and by vector analysis (vectorial aniso-TA was defined as a difference of $\geq 0.5$ in $J_{0}$ or $J_{45}$ between both eyes which is equivalent to 1.00 DC) [16]. Similar definitions applied to aniso-CA and aniso-RA. Aniso- $J_{O t}$ and aniso- $J_{45 t}$ are $J_{O}$ and $J_{45}$ of vectorial aniso-TA. Aniso- $J_{O c}$ and aniso- $J_{45 c}$ are $J_{0}$ and $J_{45}$ of vectorial aniso-CA. Aniso- $J_{0 r}$ and aniso- $J_{45 r}$ are $J_{0}$ and $J_{45}$ of vectorial anisoCA. Group A included children with vectorial aniso-TA, and the others belonged to group B. Group $\mathrm{C}$ included children with vectorial aniso-CA, and the others belonged to group D. Group E included children with vectorial aniso-RA, and the others belonged to group F. Group $\mathrm{G}$ included children with non-vectorial aniso-TA, and the others belonged to group $\mathrm{H}$.

\section{Statistical analysis}

All statistical analyses were performed using the Statistical Package for the Social Sciences (SPSS V.13.0; IBM, Chicago, IL, USA). Two-sample t-test was employed for comparisons of means and chi-square test was employed for comparison of proportions while comparing the characteristics of children included in the analysis with those excluded due to missing data. Prevalence of anisoTA was compared between boys and girls and between 61- to 66-month-old children and 67- to 72-month-old children. Spearman correlation coefficient $(\rho)$ was used to evaluate the relationships among the components of aniso-astigmatism. Comparisons of interocular difference in biometric parameters were performed between children with vs. without vectorial aniso-astigmatism (Mann-Whitney U test). Chi-square tests for categorical variables and $\mathrm{t}$-tests for continuous variables were used for detection of potentially associated factors. Variables with a P-value $<0.05$ were kept in the multivariate logistic regression models. The forward variable selection was performed to determine statistically significant risk factors for each type of aniso-astigmatism. Odds ratios (OR) and their 95\% confidence intervals (95\% CI) were calculated. All statistical tests were two-sided and $P<0.05$ was considered statistically significant.

\section{Results}

\section{Prevalence of aniso-TA}

Among 2300 eligible preschoolers, 1920 (participation rate $83.48 \%$ ) children were examined. A total of 404 children were uncooperative and no refraction measurements or biometric parameters from right or left eyes were obtained after several attempts. Guardians of 385 children did not complete the questionnaires, leaving 1131 children (58.90\% of eligible participants) included in this study.

There were no significant differences in characteristics of children (including age, gender, prevalence rate of aniso-TA) between children included in the analysis and those excluded from analysis due to missing data in questionnaire.

The mean $( \pm$ SD) age was $66.90 \pm 3.38$ months and $53.31 \%$ of participants were boys. Han nationality children $(1117,98.76 \%$ ) constituted the majority of the population. The prevalence of TA $\geq 1.00 \mathrm{DC}$ was $12.56 \%$ (95\% CI $=10.62$ to $14.49 \%)$ in right eye and $12.73 \%(95 \%$ $\mathrm{CI}=10.79$ to $14.68 \%)$ in left eye. Table 1 shows the prevalence of aniso-TA stratified by sex and age. The prevalence of non-vectorial aniso-TA was $1.95 \%$, while the prevalence of vectorial aniso-TA was $3.89 \%$. Neither non-vectorial aniso-TA nor vectorial aniso-TA varied with sex or age (all $P>0.05$ ). Forty-four children had vectorial aniso-TA. Of them, 26 children had aniso- $J_{O t} \geq$ $0.5,24$ children had aniso- $J_{45 t} \geq 0.5$, and six children had both. In addition, the prevalence of non-vectorial anisoTA $\geq 2.00 \mathrm{DC}$ was $0.18 \%$ and none had non-vectorial aniso-TA $\geq 3.00 \mathrm{DC}$.

\section{The components of vectorial aniso-astigmatism}

There was a statistically significant association between aniso- $J_{O \mathrm{t}}$ and aniso- $J_{O \mathrm{c}}(\rho=0.15, P<0.001)$, and also between aniso- $J_{45 \mathrm{t}}$ and aniso- $J_{45 \mathrm{c}} \quad(\rho=0.11, \quad P<0.001)$. There was a statistically significant association between aniso- $J_{O \mathrm{t}}$ and aniso- $J_{O \mathrm{r}}(\rho=0.22, P<0.001)$, and also between aniso- $J_{45 \mathrm{t}}$ and aniso- $J_{45 \mathrm{r}}(\rho=0.11, P<0.001)$.

\section{Comparison between groups towards interocular biometric parameters}

Table 2 shows comparisons of interocular differences in ocular biometric parameters between groups with vs. without aniso-astigmatism. Absolute value of interocular differences in AL, mean CR, AL/CR, CCT, ACD, LT were calculated. The absolute value of interocular differences in AL, CR and AL/CR, ACD were significantly different between group $\mathrm{A}$ and group $\mathrm{B}(P=0.001, P<$ $0.001, P=0.001$, and $P=0.01$ respectively). The absolute value of interocular differences in $C R$ and AL/CR were significantly different between group $C$ and group $D$ (both $P<0.001$ ), which were also significantly different between group $\mathrm{E}$ and group $\mathrm{F}$ (both $P<0.001$ ). The 
Table 1 Prevalence of aniso- total astigmatism stratified by sex and age

\begin{tabular}{|c|c|c|c|c|c|}
\hline Characteristics & N (\%) & $\begin{array}{l}\text { Vectorial aniso-TA }{ }^{a} \\
\mathrm{~N}(\%, 95 \mathrm{Cl})\end{array}$ & $P$ & $\begin{array}{l}\text { Non-vectorial aniso-TA } \\
\mathrm{N}(\%, 95 \mathrm{Cl})\end{array}$ & $P$ \\
\hline Sex & & & 0.77 & & 0.74 \\
\hline Boys & $603(53.3 \%)$ & $22(3.65 \%, 2.15-5.15)$ & & $13(2.16 \%, 0.99-3.32)$ & \\
\hline Girls & $528(46.7 \%)$ & $22(4.17 \%, 2.46-5.88)$ & & $9(1.70 \%, 0.60-2.81)$ & \\
\hline Age (month) & & & 0.82 & & 0.71 \\
\hline $61-66$ & $546(48.3 \%)$ & $20(3.66 \%, 2.08-5.24)$ & & $12(2.20 \%, 0.95-3.43)$ & \\
\hline $67-72$ & $685(51.7 \%)$ & $24(3.50 \%, 2.12-4.88)$ & & $10(1.71 \%, 0.66-2.76)$ & \\
\hline Total & 1131 (100\%) & $44(3.89 \%, 2.76-5.02)$ & & $22(1.95 \%, 1.14-2.75)$ & \\
\hline
\end{tabular}

$\mathrm{N}$ number, $\mathrm{Cl}$ confidence interval

${ }^{a}$ Vectorial aniso-TA was defined as a difference of $\geq 0.5$ in $J_{0}$ or $J_{45}$ between the two eyes

${ }^{b}$ Non-vectoral aniso-TA was defined as the difference of $\geq 1.0$ diopter cylinder in absolute cylinder between the two eyes regardless of axis

absolute value of interocular differences in $\mathrm{AL}, \mathrm{CR}$ and $\mathrm{AL} / \mathrm{CR}$ were significantly different between group $\mathrm{G}$ and group $\mathrm{H}(P<0.001, P=0.001$, and $P<0.001$ respectively).

\section{Risk factors for aniso-astigmatism}

Comparisons for each risk factor between group A and group B were shown in sTable 1. Children in group A were more likely to have abnormal 5 min-Apgar score $(P<0.001)$ and parental astigmatism $(P=0.03)$ than those in group $B$. In the multivariate analysis, two variables remained significantly associated with vectorial aniso-TA: 5 min-Apgar score and parental astigmatism. Children with 5 min-Apgar score lower than 7 were 6.42 times as likely to have vectorial aniso-TA as children with normal Apgar score $(95 \% \mathrm{CI}=2.63-15.69, \quad P<$
0.001 ). Children with parental astigmatism were 2.03 times as likely to have vectorial aniso-TA as children without parental astigmatism $(95 \% \mathrm{CI}=1.09-3.79, P=$ 0.03).

Comparisons for each risk factor between group $\mathrm{C}$ and group D were shown in sTable 2. Children in group $\mathrm{C}$ were more likely to have older father at child birth $(P=$ $0.047)$, pre-term delivery $(P=0.01)$, more outdoor activity $(P=0.03)$ and being twin or triple $(P=0.03)$ than those in group D. In the multivariate logistic regression analysis, two variables remained significantly associated with vectorial aniso-CA: being twin or triple and term delivery (Table 3). Children being twin or triple were 2.43 times as likely to have vectorial aniso-CA as those being monotocous $(95 \% \mathrm{CI}=1.05-5.60, P=0.04)$. Preterm delivery $(\mathrm{OR}=2.60,95 \% \mathrm{CI}=1.09-6.15, \quad P=0.03)$

Table 2 Comparisons of interocular differences in ocular biometric parameters between groups with vs. without aniso-astigmatism

\begin{tabular}{|c|c|c|c|c|c|c|c|c|c|c|c|c|}
\hline & \multicolumn{2}{|l|}{$\mathrm{AL}(\mathrm{mm})$} & \multicolumn{2}{|l|}{ MCR (mm) } & \multicolumn{2}{|l|}{$A L / C R$} & \multicolumn{2}{|l|}{$\mathrm{CCT}(\mathrm{mm})$} & \multicolumn{2}{|l|}{$\mathrm{ACD}(\mathrm{mm})$} & \multicolumn{2}{|l|}{$\mathrm{LT}(\mathrm{mm})$} \\
\hline & Mean \pm SD & $P$ & Mean \pm SD & $P$ & Mean \pm SD & $P$ & Mean \pm SD & $P$ & Mean \pm SD & $P$ & Mean \pm SD & $P$ \\
\hline $\begin{array}{l}\text { Vectorial aniso-TA } \\
\text { group (N) }\end{array}$ & & 0.001 & & $<0.001$ & & 0.001 & & 0.19 & & 0.01 & & 0.09 \\
\hline Group A (44) & $0.19 \pm 0.24$ & & $0.12 \pm 0.09$ & & $0.05 \pm 0.05$ & & $9.50 \pm 17.17$ & & $0.09 \pm 0.09$ & & $0.10 \pm 0.10$ & \\
\hline Group B (1087) & $0.11 \pm 0.14$ & & $0.07 \pm 0.07$ & & $0.03 \pm 0.03$ & & $7.59 \pm 14.27$ & & $0.06 \pm 0.08$ & & $0.07 \pm 0.09$ & \\
\hline $\begin{array}{l}\text { Vectorial aniso-CA } \\
\text { group }(\mathrm{N})\end{array}$ & & 0.89 & & $<0.001$ & & $<0.001$ & & 0.30 & & 0.79 & & 0.78 \\
\hline Group C (278) & $0.11 \pm 0.14$ & & $0.11 \pm 0.09$ & & $0.04 \pm 0.04$ & & $7.54 \pm 14.74$ & & $0.06 \pm 0.07$ & & $0.08 \pm 0.09$ & \\
\hline Group D (853) & $0.11 \pm 0.14$ & & $0.06 \pm 0.06$ & & $0.03 \pm 0.03$ & & $7.70 \pm 14.29$ & & $0.06 \pm 0.08$ & & $0.07 \pm 0.10$ & \\
\hline $\begin{array}{l}\text { Vectorial aniso-RA } \\
\text { group }(\mathrm{N})\end{array}$ & & 0.48 & & $<0.001$ & & $<0.001$ & & 0.36 & & 0.42 & & 0.87 \\
\hline Group E (273) & $0.12 \pm 0.15$ & & $0.11 \pm 0.09$ & & $0.04 \pm 0.04$ & & $7.95 \pm 15.18$ & & $0.06 \pm 0.07$ & & $0.07 \pm 0.08$ & \\
\hline Group F (858) & $0.11 \pm 0.14$ & & $0.06 \pm 0.06$ & & $0.03 \pm 0.03$ & & $7.57 \pm 14.14$ & & $0.06 \pm 0.08$ & & $0.08 \pm 0.10$ & \\
\hline $\begin{array}{l}\text { Non-vectorial aniso-TA } \\
\text { group }(\mathrm{N})\end{array}$ & & $<0.001$ & & 0.001 & & $<0.001$ & & 0.97 & & 0.81 & & 0.68 \\
\hline Group G (22) & $0.28 \pm 0.30$ & & $0.13 \pm 0.09$ & & $0.06 \pm 0.06$ & & $8.95 \pm 17.20$ & & $0.06 \pm 0.06$ & & $0.07 \pm 0.09$ & \\
\hline Group H(1109) & $0.10 \pm 0.14$ & & $0.07 \pm 0.07$ & & $0.03 \pm 0.03$ & & $7.63 \pm 14.34$ & & $0.06 \pm 0.08$ & & $0.07 \pm 0.09$ & \\
\hline
\end{tabular}

All numbers showed in this table were calculated as absolute values of interocular deviation with a form of mean \pm standard deviation

$A L$ axial length, $M C R$ mean corneal curvature radius, $C C T$ central corneal thickness, $A C D$ anterior chamber depth, $L T$ lens thickness, $S D$ standard deviation, $N$ number 
Table 3 Independent Risk Factors for vectorial aniso-CA from Multivariate Logistic Regression

\begin{tabular}{llll}
\hline & \multicolumn{3}{l}{ Multivariate analysis } \\
\cline { 2 - 4 } Risk factors & Adjusted OR & $\mathbf{9 5 \%} \mathrm{Cl}$ & $\mathbf{P}$ \\
\hline Twin or triple (Yes vs No) & 2.43 & $1.05-5.60$ & 0.04 \\
Term delivery & & & \\
Full-term & Reference & & \\
Pre-term & 2.60 & $1.09-6.15$ & 0.03 \\
$\quad$ Post-term & 3.61 & $1.31-9.96$ & 0.01 \\
\hline OR odds ratio, Cl confidence interval & &
\end{tabular}

and post-term delivery $(\mathrm{OR}=3.61,95 \% \mathrm{CI}=1.31-9.96$, $P=0.01$ ) were more likely to have vectorial aniso-CA than full-term delivery.

Comparisons for each risk factor between group $\mathrm{E}$ and group F were shown in sTable 3 and no statistically significant difference was found. Likewise, no statistically significant variable was found to be associated with vectorial aniso-RA in the multivariate logistic regression analysis. Comparisons for each risk factor between group $\mathrm{G}$ and group $\mathrm{H}$ were shown in sTable 4. Children in group $\mathrm{G}$ were more likely to have younger paternal age at child birth, $(P=0.049)$ abnormal 5 min-Apgar score $(P=0.03)$ than those in group $H$. In the multivariate logistic regression analysis, only 5 min-Apgar score remained significantly associated with non-vectorial aniso-TA. Children with 5 min-Apgar score lower than 7 were 4.99 times as likely to have non-vectorial aniso-TA as children with normal Apgar score $(95 \% \mathrm{CI}=1.41-$ 17.68, $P=0.01)$.

\section{Discussion}

This study describes, for the first time to our knowledge, the prevalence of aniso-TA using both non-vectorial aniso-TA and vectorial aniso-TA in Chinese preschool children. The prevalence of vectorial aniso-TA was twice as common as non-vectorial aniso-TA, which did not vary with sex and age. The prevalence of aniso-TA was much lower than that of TA.

Prevalence of aniso-TA from previous studies on similar age population was shown in Table 4. These studies reported different prevalence rate, which might be due to different ethnicity, age, and whether vectorial analysis was used. We compared the prevalence of non-vectorial aniso-TA with previous studies defined as $\geq 1.0 \mathrm{DC}$. The prevalence of non-vectorial aniso-TA in the present study was lower than that found in the Tohono O'odham Native American children, in the Northern Ireland Childhood Errors of Refraction (NICER) study and in the rural area of southwestern Japan [25, 26, 29]. However, it was higher than that in the Sydney Myopia Study, and similar to that in the Sydney Paediatric Eye Disease Study [14, 28]. Among these studies, the prevalence of non-vectorial aniso-TA found in the Tohono O'odham Native American children was the highest, in accordance with the population's high TA prevalence [27, 29]. When compared with the Shandong Children Eye Study, which was also carried out among Chinese children, the prevalence in this study was lower [15]. Our previous study also showed the TA prevalence was lower than that from The Shandong Children Eye Study [20, 30]. Few studies revealed the prevalence of vectorial aniso-TA. The prevalence of vectorial aniso-TA in the present study was lower than that found in the Multi-Ethnic Pediatric Eye Disease Study (MEPEDS) [16]. In their study, vectorial aniso-TA was twice as common as non-vectorial aniso-TA, similar with our results. Children in MEPEDS were African American and Hispanic, who also showed higher TA prevalence. The difference between non-vectorial aniso-TA prevalence and vectorial aniso-TA prevalence was reasonable as vectorial aniso-TA took astigmatic axis into consideration.

Whatever definition was used, aniso-TA was associated not only with increased interocular differences in $\mathrm{CR}$, but also with AL, possibly due to the relationship among aniso-TA and anisometropia. A similar correlation was reported by Huynh et al. [14], O'Donoghue et al. [25], Singh et al. [31], and Hameshi et al. [32]. These studies showed non-vectorial aniso-CA was associated with non-vectorial aniso-TA. This finding is in agreement with our knowledge that most aniso-TA of the eyes is due to corneal issues. Interestingly, we found that interocular differences in ACD were associated with vectorial aniso-TA. The finding is in accordance with Hameshi et al., but contradicts with the results of the NICER Study [25, 32]. Vectorial aniso-CA and vectorial aniso-RA can only be explained by interocular differences in CR.

This study revealed that parental astigmatism was a risk factor for vectorial aniso-TA. Our previous article has presented the contradictory results from different studies on the genetic contribution to astigmatism [21]. Similar condition exists on the genetic contribution to aniso-astigmatism. Recently, a population-based twin study showed that the correlation between monozygotic twins for aniso-CA were significantly different from dizygotic twins [33]. A study in Korea found that intraclass correlation coefficients for spherical equivalent and ocular biometrics were significantly higher in monozygotic twins compared with singleton, with greater consistency and conformity [34]. However, another study did not find any significant difference between children being twin or siblings in refractive error, corneal curvature, ACD and CCT [35]. Further investigations may be needed to clarify the relationship between genetics and aniso-astigmatism. 


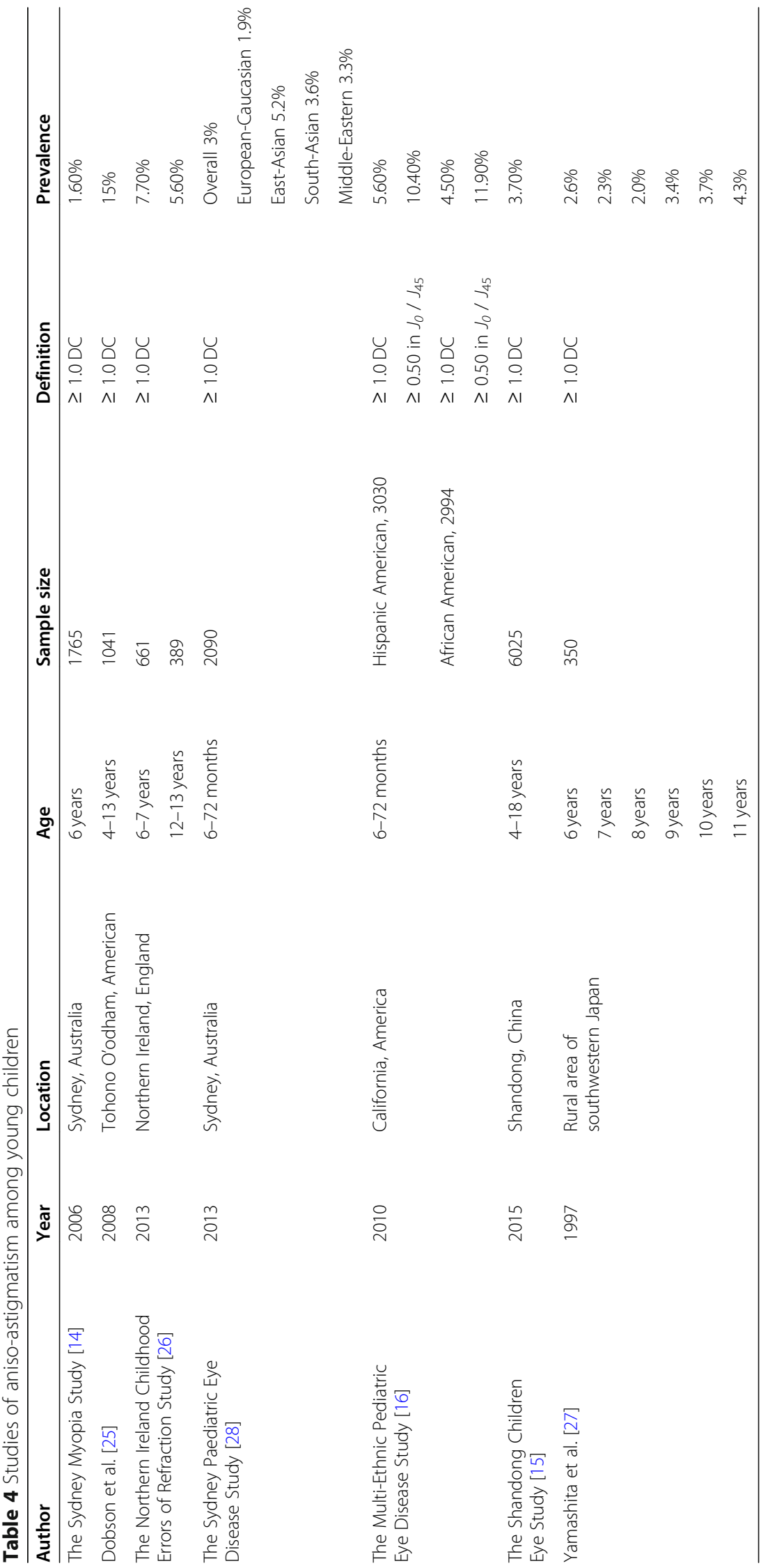


Our study showed that children with a 5-min Apgar score $<7$ had a higher likelihood of developing aniso-TA at 5- to 6-years compared to those with an Apgar score of 7-10 (within the normal range), while pre-term or post-term delivery were risk factors for vectorial anisoCA. A previous study found asymmetrical growth restriction in perterm-born children [36]. Dubois reported structural asymmetries of perisylvian regions in the preterm newborn [37]. Additionally, several studies have found abnormal nervous system function in preterm born children. Michalczuk suggested that Apgar score seemed to be a predicting factor for developmental rate of brain function in children with history of prematurity [38]. Teli found that low 5-min Apgar score in very perterm infants hindered corpus callosum microstructural development [39]. Moreover, eye growth is parellel to neurodevelopment. White matter changes were found in children with anisometropic amblyopia [40]. It has also been reported that low 5-min Apgar score increased the risk of reduced vision in children [41]. The Sydney Myopia Study found that paternal age $>35$ years was accociated with non-vectorial aniso-TA in unadjusted analyses. After multivariable adjustment, breast feeding had a significant protective association $(P=0.02)$ with non-vectorial aniso-TA. In our study, neither paternal age $>35$ years or breast feeding was a risk factor for nonvectorial aniso-TA. To sum up, intrauterine hypoplasia and poor birth condition may be associated with asymmeric whole body development, neurodevelopment, and asymmeric visual and refractive development such as aniso-astigmatism. Further work is required to clarify the developmental mechanism behind these associations.

Astigmatism is relatively complicated because of its vectorial feature. Both non-vectorial analysis and vectorial analysis were included in this study. The former only considers the cylinder power of aniso-astigmatism and neglects its axis. The latter, used frequently now to decompose aniso-astigmatism, also has its limitation as it splits aniso-astigmatism to two directions. However, how to integrate $J_{0}$ and $J_{45}$ difference is still a problem. Both methods describing aniso-astigmatism have their shortcomings but we hope to improve understanding and promote exploration of aniso-astigmatism using these two methods together.

The strengths of this study include its populationbased design, large sample size, and standardized examination protocols performed by an expert team, risk factors during pregnancy and early childhood. Our analyses are different from most previous studies by considering vectorial features of aniso-astigmatism. The limitation of this study is that some eligible children were not included into the anaysis due to missing data in questionnaire or refractive error measures, the risk factor data collected through questionnaire may be subjective and biased. What' more, this study is also limited in the use of refraction data under noncyloplegic condition. Autorefractors have been widely used in vision screening, clinical practice, and researches, especially in epidemiological surveys and clinical trials, to check the refractive status of children. Fogging mechanisms were usually built-in to reduce influence of accommodation, whereas the influence could not be fully eliminated. Several studies have demonstrated that noncycloplegic autorefraction has reasonable accuracy and repeatability compared with cycloplegic retinoscopy [42-44]. A previous study measures refraction before and after cycloplegia using the autorefractor Canon RK-F1. Results showed statistically significant differences between the cycloplegic and noncycloplegic spherical powers, but insignificant differences between the cycloplegic and noncycloplegic cylindrical values [42]. A study among Chinese children found significant differences between cycloplegic and non-cycloplegic spherical euivalent using Canon RK-F1, but insignificant differences between cycloplegic and non-cycloplegic $J_{0}$ and $J_{45}$ [43]. Another recent study showed that measurements obtained with the closedfield autorefractor Topcon KR-800 without cycloplegia had good reliability for the evaluation of spherical equivalent and $J_{0}$, indicating that it has reliable accuracy of measurement of the "with-the-rule" and "against-therule" astigmatism, whereas agreement with cycloplegic retinoscopy for the evaluation of $J_{45}$ was fair to good, indicating potential limitations for the detection of oblique astigmatism [44]. Cycloplegia may bring vision discomfort, inconvenience, and allergic reaction and takes time. Thus it's less accepted by children and guardians. Actually, it's hard to achieve cycloplegic measurements at high proportion among preschool children. We admit that noncycloplegic autorefraction has its shortage but still we think it can provide referable measurements for cylindrical power. We didn't include noncycloplegic spherical data considering the relatively more significant influence of cycloplegia on spherical euivalent. It has been reported that for children, when cycloplegic refraction is difficult to perform, AL/CR may be the second choice in predicting spherical equivalent $[45,46]$. Therefore we include AL/CR in the analyses instead.

\section{Conclusions}

In summary, in the 61- to 72-month-old children in the Yuhuatai District, the prevalence of non-vectorial anisoTA was $1.95 \%$, while the prevalence of vectorial anisoTA was twice as common as non-vectorial aniso-TA. Both CR and AL asymmetry were correlated with anisoTA. Children with 5-min Apgar score $<7$ were more likely to have aniso-TA, while twin or triple, pre-term or post-term delivery were more likely to have vectorial aniso-CA. 


\section{Supplementary Information}

The online version contains supplementary material available at https://doi. org/10.1186/s12886-021-01808-7.

Additional file 1: Table S1. Distribution of Risk Factors in Children With vs. Without Vectorial Aniso-Total Astigmatism.

Additional file 2: Table S2. Distribution of Risk Factors in Children With vs. Without Vectorial Aniso-Corneal Astigmatism.

Additional file 3: Table S3. Distribution of Risk Factors in Children With vs. Without Vectorial Aniso-Residual Astigmatism.

Additional file 4: Table S4. Distribution of Risk Factors in Children With vs. Without Non-Vectorial Aniso-Total Astigmatism.

\section{Abbreviations}

TA: Total Astigmatism; CA: Corneal Astigmatism; RA: Resiual Astigmatism; DC: Dioptre Cylinder; CCT: Central Corneal Thickness; CR: Corneal Radius; ACD: Anterior Chamber Depth; LT: Lens Thickness; AL: Axial Length

\section{Acknowledgements}

The authors would like to thank the children, their parents or legal guardians, and all the members of the Maternal and Child Healthcare Hospital of Yuhuatai District, Nanjing, China, for their helpful advice and support. The authors would also like to thank Xin Xu, a statistician in Nanjing Medical University for her statistical help.

\section{Authors' contributions}

Study concept and design ( $\mathrm{DH}, \mathrm{HZ}, \mathrm{XC})$; data collection ( $\mathrm{HT}, \mathrm{QH}, \mathrm{YW}, \mathrm{RL}, \mathrm{QS}$, $X Z 1$ and $X Z 2$, with XZ1 corresponding to Xiaoyan Zhao); analysis and interpretation of data $(\mathrm{HT}, \mathrm{QH}, \mathrm{ZW})$; drafting of the manuscript $(\mathrm{HT}, \mathrm{QH}, \mathrm{ZW}$ ); critical revision of the manuscript ( $\mathrm{ZW}, \mathrm{HL})$; supervision $(\mathrm{HL})$. All authors read and approved the final manuscript.

\section{Funding}

This study was funded by the National Natural Science Foundation of China (Grant No. 81673198;No. 81803258); the Natural Science Foundation of Jiangsu Province (Grant No. BK20161595); Jiangsu Province's Key Provincial Talents Program (Grant No. QNRC2016563). The sponsor or funding organization had no role in the design or conduct of this research.

\section{Availability of data and materials}

Data can be shared upon request.

\section{Ethics approval and consent to participate}

This study was approved by the ethics committee of the Nanjing Medical University. Written consent was obtained from the parents or guardians of all children

\section{Consent for publication}

Not Applicable.

\section{Competing interests}

The authors declare that they have no competing interests.

\section{Author details}

${ }^{1}$ Department of Ophthalmology, The First Affiliated Hospital with Nanjing Medical University, 300 Guangzhou Road, Nanjing 210029, China. ${ }^{2}$ Department of Ophthalmology, Maternal and Child Healthcare Hospital of Yuhuatai District, Nanjing, China. ${ }^{3}$ Department of Ophthalmology, Wuxi Children's Hospital, Wuxi, China. ${ }^{4}$ Department of Child Healthcare, The First Affiliated Hospital with Nanjing Medical University, Nanjing, China.

Received: 1 June 2020 Accepted: 7 January 2021

Published online: 03 February 2021

\section{References}

1. Chuck RS, Jacobs DS, Lee JK, Afshari NA, Vitale S, Shen TT, et al. Refractive Errors \& Refractive Surgery Preferred Practice Pattern(R). Ophthalmology. 2018;125(1):1-p104.
2. Read SA, Vincent SJ, Collins MJ. The visual and functional impacts of astigmatism and its clinical management. Ophthalmic Physiol Opt. 2014; 34(3):267-94.

3. Tarczy-Hornoch K. Accommodative lag and refractive error in infants and toddlers. J AAPOS. 2012;16(2):112-7.

4. Twelker JD, Miller JM, Sherrill DL, Harvey EM. Astigmatism and myopia in Tohono O'odham native American children. Optom Vis Sci. 2013;90(11): 1267-73.

5. Fan DS, Rao SK, Cheung EY, Islam M, Chew S, Lam DS. Astigmatism in Chinese preschool children: prevalence, change, and effect on refractive development. Br J Ophthalmol. 2004;88(7):938-41.

6. Smith EL 3rd, Hung LF, Arumugam B, Wensveen JM, Chino YM, Harwerth RS. Observations on the relationship between anisometropia, amblyopia and strabismus. Vis Res. 2017;134:26-42.

7. Barrett BT, Bradley A, Candy TR. The relationship between anisometropia and amblyopia. Prog Retin Eye Res. 2013;36:120-58.

8. South J, Gao T, Collins A, Turuwhenua J, Robertson K, Black J. Aniseikonia and anisometropia: implications for suppression and amblyopia. Clin Exp Optom. 2019;102:556-65.

9. Lee JY, Seo JY, Baek SU. The effects of glasses for anisometropia on stereopsis. Am J Ophthalmol. 2013;156(6):1261-6 e1.

10. Ying GS, Huang J, Maguire MG, Quinn G, Kulp MT, Ciner E, et al. Associations of anisometropia with unilateral amblyopia, interocular acuity difference, and stereoacuity in preschoolers. Ophthalmology. 2013;120(3): 495-503.

11. Liu F, Yang X, Tang A, Liu L. Association between mode of delivery and astigmatism in preschool children. Acta Ophthalmol. 2018;96(2):e218-e21.

12. McKean-Cowdin R, Varma R, Cotter SA, Tarczy-Hornoch K, Borchert MS, Lin $\mathrm{JH}$, et al. Risk factors for astigmatism in preschool children: the multi-ethnic pediatric eye disease and Baltimore pediatric eye disease studies. Ophthalmology. 2011;118(10):1974-81.

13. Pan CW, Ke C, Hu DN, Li J, Zhong H. Iris colour and astigmatism among Chinese teenagers. Br J Ophthalmol. 2019;103:1810-4.

14. Huynh SC, Wang XY, Ip J, Robaei D, Kifley A, Rose KA, et al. Prevalence and associations of anisometropia and aniso-astigmatism in a population based sample of 6 year old children. Br J Ophthalmol. 2006:90(5):597-601.

15. Hu YY, Wu JF, Lu TL, Wu H, Sun W, Guo DD, et al. Prevalence and associations of Anisometropia in children. Invest Ophthalmol Vis Sci. 2016; 57(3):979-88.

16. Borchert M, Tarczy-Hornoch K, Cotter SA, Liu N, Azen SP, Varma R, et al. Anisometropia in Hispanic and african american infants and young children the multi-ethnic pediatric eye disease study. Ophthalmology. 2010;117(1): $148-53$ e1.

17. Dobson V, Miller JM, Clifford-Donaldson CE, Harvey EM. Associations between anisometropia, amblyopia, and reduced stereoacuity in a schoolaged population with a high prevalence of astigmatism. Invest Ophthalmol Vis Sci. 2008:49(10):4427-36.

18. Chou YS, Tai MC, Chen PL, Lu DW, Chien KH. Impact of cylinder axis on the treatment for astigmatic amblyopia. Am J Ophthalmol. 2014;157(4):908-14 e1.

19. Moghaddam AA, Kargozar A, Zarei-Ghanavati M, Najjaran M, Nozari V, Shakeri MT. Screening for amblyopia risk factors in pre-verbal children using the Plusoptix photoscreener: a cross-sectional population-based study. Br J Ophthalmol. 2012;96(1):83-6.

20. Wang $Z$, Huang $D$, Chen $X$, Zhu H, Sun $Q$, Wang $Y$, et al. Preschool children exhibit evident compensatory role of internal astigmatism in distribution of astigmatism: the Nanjing eye study. Invest Ophthalmol Vis Sci. 2019;60(1): 73-81.

21. Wang Z, Tong H, Hao Q, Chen X, Zhu H, Huang D, et al. Risk factors for astigmatic components and internal compensation: the Nanjing eye study. Eye. 2020:1-9.

22. Lai S, Flatley C, Kumar S. Perinatal risk factors for low and moderate fiveminute Apgar scores at term. Eur J Obstet Gynecol Reprod Biol. 2017;210: 251-6.

23. Apgar V. A proposal for a new method of evaluation of the newborn infant Curr Res Anesth Analg. 1953:32(4):260-7.

24. Thibos LN, Wheeler W, Horner D. Power vectors: an application of Fourier analysis to the description and statistical analysis of refractive error. Optom Vis Sci. 1997;74(6):367-75.

26. O'Donoghue L, McClelland JF, Logan NS, Rudnicka AR, Owen CG, Saunders $\mathrm{KJ}$. Profile of anisometropia and aniso-astigmatism in children: prevalence 
and association with age, ocular biometric measures, and refractive status. Invest Ophthalmol Vis Sci. 2013;54(1):602-8.

27. Yamashita T, Watanabe S, Ohba N. A longitudinal study of cycloplegic refraction in a cohort of 350 Japanese schoolchildren. Ophthalmic Physiol Opt. 1999;19(1):30-3.

29. Harvey EM, Dobson V, Clifford-Donaldson CE, Green TK, Messer DH, Miller $\mathrm{JM}$. Prevalence of astigmatism in native American infants and children. Optom Vis Sci. 2010;87(6):400-5.

28. Afsari S, Rose KA, Gole GA, Philip K, Leone JF, French A, et al. Prevalence of anisometropia and its association with refractive error and amblyopia in preschool children. Br J Ophthalmol. 2013:97(9):1095-9.

25. Dobson V, Harvey EM, Miller JM, Clifford-Donaldson CE. Anisometropia prevalence in a highly astigmatic school-aged population. Optom Vis Sci. 2008;85(7):512-9.

30. Wu JF, Bi HS, Wang SM, Hu YY, Wu H, Sun W, et al. Refractive error, visual acuity and causes of vision loss in children in Shandong, China. The Shandong Children Eye Study. PLoS One. 2013:8(12):e82763.

31. Singh N, Rohatgi J, Kumar V. A prospective study of anterior segment ocular parameters in Anisometropia. Korean J Ophthalmol. 2017;31 (2):165-71.

32. Hashemi H, Khabazkhoob M, Emamian MH, Shariati M, Abdolahi-nia T, Fotouhi A. All biometric components are important in anisometropia, not just axial length. Br J Ophthalmol. 2013:97(12):1586-91.

33. Parssinen O, Kauppinen M, Halekoh U, Kaprio J, Rantanen T. Heredity of interocular similarities in components of refraction: a population-based twin study among 66- to 79-year-old female twins. Acta Ophthalmol. 2019;97(6): 603-7.

34. Kim MH, Zhao D, Kim W, Lim DH, Song YM, Guallar E, et al. Heritability of myopia and ocular biometrics in Koreans: the healthy twin study. Invest Ophthalmol Vis Sci. 2013;54(5):3644-9.

35. Sanfilippo PG, Medland SE, Hewitt AW, Kearns LS, Ruddle JB, Sun C, et al. Ophthalmic phenotypes and the representativeness of twin data for the general population. Invest Ophthalmol Vis Sci. 2011;52(8):5565-72.

36. Bocca-Tjeertes I, Bos A, Kerstjens J, de Winter A, Reijneveld S. Symmetrical and asymmetrical growth restriction in preterm-born children. Pediatrics. 2014;133(3):e650-6.

37. Dubois J, Benders M, Lazeyras F, Borradori-Tolsa C, Leuchter RH, Mangin JF, et al. Structural asymmetries of perisylvian regions in the preterm newborn. Neuroimage. 2010;52(1):32-42.

38. Michalczuk M, Urban B, Chrzanowska-Grenda B, Ozieblo-Kupczyk M, Bakunowicz-Lazarczyk A. An influence of birth weight, gestational age, and Apgar score on pattern visual evoked potentials in children with history of prematurity. Neural Plast. 2015;2015:754864.

39. Teli R, Hay M, Hershey A, Kumar M, Yin H, Parikh NA. Postnatal microstructural developmental trajectory of Corpus callosum subregions and relationship to clinical factors in very preterm infants. Sci Rep. 2018;8(1): 7550.

40. Li Q, Zhai L, Jiang Q, Qin W, Li Q, Yin X, et al. Tract-based spatial statistics analysis of white matter changes in children with anisometropic amblyopia. Neurosci Lett. 2015;597:7-12.

41. Pan CW, Qian DJ, Zhu H, Yu JJ, Liu H. Apgar score and reduced vision in children aged 3 to 6 years. Graefes Arch Clin Exp Ophthalmol. 2017;255(2): 401-5.

42. Akil H, Keskin S, Çavdarli C. Comparison of the refractive measurements with hand-held autorefractometer, table-mounted autorefractometer and cycloplegic retinoscopy in children. Korean J Ophthalmol. 2015;29(3):178-84.

43. Li T, Zhou X, Zhu J, Tang X, Gu X. Effect of cycloplegia on the measurement of refractive error in Chinese children. Clin Exp Optom. 2019;102(2):160-5.

44. Kuo YC, Wang JH, Chiu CJ. Comparison of open-field autorefraction, closedfield autorefraction, and retinoscopy for refractive measurements of children and adolescents in Taiwan. J Formos Med Assoc. 2020;119(8):1251-8.

45. He X, Zou H, Lu L, Zhao R, Zhao H, Li Q, et al. Axial length/corneal radius ratio: association with refractive state and role on myopia detection combined with visual acuity in Chinese schoolchildren. PLoS One. 2015; 10(2):e0111766.

46. Foo VH, Verkicharla PK, Ikram MK, Chua SY, Cai S, Tan CS, et al. Axial length/ corneal radius of curvature ratio and myopia in 3-year-old children. Transl Vis Sci Technol. 2016;5(1):5

\section{Publisher's Note}

Springer Nature remains neutral with regard to jurisdictional claims in published maps and institutional affiliations.

\section{Ready to submit your research? Choose BMC and benefit from:}

- fast, convenient online submission

- thorough peer review by experienced researchers in your field

- rapid publication on acceptance

- support for research data, including large and complex data types

- gold Open Access which fosters wider collaboration and increased citations

- maximum visibility for your research: over $100 \mathrm{M}$ website views per year

At BMC, research is always in progress.

Learn more biomedcentral.com/submissions 